\title{
Изоляция устьев легочных вен электродами без функции охлаждения
}

\author{
Доронин А. В. ${ }^{1}$, Суслина Ю. И. ${ }^{2}$, Резник А. С. ${ }^{2}$, Ханенова В. А. ${ }^{2}$, Марушко Е. Ю. ${ }^{2}$, \\ Мешкова М.C. ${ }^{2}$
}

\begin{abstract}
${ }^{1}$ Национальная медицинская академия последипломного образования имени П. Л. Шупика (Киев) ${ }^{2}$ ГУ «Научно-практический медицинский центр детской кардиологии и кардиохирургии МЗ Украины»
\end{abstract} (Киев)

\begin{abstract}
В статье анализируется собственный опыт изоляции устьев легочных вен при радиочастотной катетерной деструкции фибрилляции предсердий (ФП) электродами 4 мм без функции охлаждения. Проанализированы результаты 145 первичных последовательных катетерных деструкций ФП у пациентов с пароксизмальной формой ФП. После 15-20 аппликаций деструкционный электрод извлекался и протирался.

Среднее время рентген-экспозиции составило $25,2 \pm 6,3$ мин. Рецидив ФП на протяжении 1 года произошел у $43(29,7 \%)$ пациентов, еще у $1(0,7 \%)$ возникло типичное ТП, у $1-$ предсердная тахикардия, у $1-$ левостороннее ТП. Синусовый ритм сохранялся без применения антиаритмических препаратов на протяжении года у $99(68,3 \%)$ пациентов.

Осложнения в результате проведения процедуры произошли у $4(2,8 \%)$ пациентов: у $2(1,4 \%)$ - тампонада перикарда, потребовавшая перикардиоцентеза, у $2(1,4 \%)$ - выпот в перикарде (пациенты лечились консервативно).
\end{abstract}

Таким образом, данная методика является достаточно эффективной и безопасной.

Ключевые слова: фибрилляция предсердий, изоляция легочных вен, эффективность.

Радиочастотная катетерная деструкция фибрилляции предсердий (ФП) в настоящее время достаточно эффективна и безопасна [1]. Согласно экспертному консенсусу от 2017 года, обязательным элементом при катетерной деструкции ФП является изоляция легочных вен (класс I, уровень доказанности А) [2]. Первым катетерную изоляцию легочных вен с использованием циркулярного диагностического электрода, расположенного в устье вены (сегментарную изоляцию), предложил в 2000 году Haissaguerre [3]. Позже была предложена широкая изоляция легочных вен - попарно левых и правых [4].

Последующие рандомизированные исследования показали, что широкая попарная изоляция легочных вен с верификацией блокады проведения является более эффективной, чем сегментарная изоляция каждой вены отдельно [5].

Хотя широкую изоляцию легочных вен предпочитают применять многие электрофизиологи, она может создавать субстрат для возникновения левопредсердных тахикардий [6]. Изоляция легочных вен ближе к устью может снизить частоту возникновения левопредсердных тахикардий. Уменьшение длины линии аппликаций может привести к снижению рецидивов фибрилляции предсердий. Однако нанесение аппликаций вблизи устьев может увеличивать опасность развития стеноза легочных вен [7].
При пароксизмальной форме ФП синусовый ритм сохраняется в течение года после одной катетерной деструкции без применения антиаритмических препаратов у $50-60 \%$ пациентов $[2,8]$.

Цель работы - проанализировать собственный опыт изоляции устьев легочных вен электродом без функции охлаждения.

Материалы и методы. В период с 01.2013 по 12.2015 г. в ГУ «Научно-практический медицинский центр детской кардиологии и кардиохирургии МЗ Украины» было произведено 159 первичных последовательных катетерных деструкций ФП у пациентов с пароксизмальной формой ФП. Связь была утеряна с 14 пациентами. В подавляющем большинстве это были пациенты, прооперированные в 2013 году. Таким образом, в анализируемую группу вошли $145(91,2 \%)$ пациентов.

В группе было 74 (51,0\%) женщины. Средний возраст составил $57,3 \pm 7,6$ года.

У $96(66,2 \%)$ пациентов диагностирована гипертоническая болезнь, у $22(15,2 \%)$ - заболевания щитовидной железы, у 3 (3,0\%) - ИБС, у 14 (9,7\%) - сахарный диабет, у $3(2,0 \%)$ - мочекаменная болезнь, 3 (2,0\%) пациента перенесли инсульт, у $1(0,7 \%)$ пациентки была выполнена пластика митрального клапана. Все пациенты получали антикоагулянты в течение четырех недель перед проведением процедуры. Антиаритмические препараты перед процедурой не отменялась. 
У $32(22,1 \%)$ пациентов было сопутствующее истмус-зависимое трепетание предсердий (ТП), у $2(1,2 \%)$ - левопредсердная тахикардия, у $1(0,7 \%)$ - re-entry тахикардия атриовентрикулярного узла.

Процедура проводилась под интубационным наркозом, через двойную транссептальную пункцию. Пункция осуществлялась с использованием чреспищеводного ультразвукового датчика. Вначале производилась изоляция легочных вен. Использовались катетеры с дистальным электродом 4 мм без функции охлаждения. Аппликации наносились по внешнему краю электрода «Lasso», расположенного в устье легочной вены. После каждых 15-20 аппликаций деструкционный электрод извлекался и протирался влажной салфеткой. После этого транссептальный катетер промывался физиологическим раствором с добавлением гепарина. Количество воздействий на одной легочной вене не должно было превышать 40 аппликаций.

Если в конце процедуры тахикардия продолжалась, ритм восстанавливался ЭИТ. Максимальная мощность воздействия -35 Ватт, температура $-55^{\circ} \mathrm{C}$, время аппликации - 40 секунд.

Результаты. Среднее время рентген-экспозиции составило 25,2 $\pm 6,3$ мин. Количество аппликаций $87,7 \pm 24,2$. Длительность процедуры - 2,2 $\pm 0,8$ часа.

Рецидив ФП на протяжении 1 года произошел у 43 $(29,7 \%)$ пациентов, еще у $1(0,7 \%)$ возникло типичное ТП, у $1(0,7 \%)$ - предсердная тахикардия, у $1(0,7 \%)-$ левостороннее ТП. Синусовый ритм сохранялся без применения антиаритмических препаратов на протяжении года у $99(68,3 \%)$ пациентов. Антиаритмическими препаратами удалось удержать синусовый ритм еще у $9(6,2 \%)$ пациентов, у $6(4,1 \%)$ приступы тахикардии стали редкими либо непродолжительными. Таким образом, положительный эффект удалось получить у 114 $(78,6 \%)$ пациентов. У $1(0,7 \%)$ пациента наблюдалось увеличение частоты пароксизмов ФП.

Было $2(1,4 \%)$ случая тампонады перикарда, потребовавшие перикардиоцентеза, и $2(1,4 \%)$ случая выпота в перикарде, которые лечились консервативно.
Осложнений, которые можно было связать с использованием электродов без функции охлаждения, зафиксировано не было.

Выводы. Изоляция устьев легочных вен с использованием электродов без функции охлаждения с протиранием их через каждые 15 аппликаций при пароксизмальной форме ФП является достаточно эффективной и безопасной. При этом наблюдается минимальное число случаев левостороннего ТП и осложнений. Рентген-экспозиция также находится в пределах значений, публикуемых в литературе.

\section{Литература}

1. Updated world wide survey on the methods, efficacy, and safety of catheter ablation for human atrial fibrillation / Cappato R., Calkins H., ChenS. A. et al. // Circ. Arrhythm. Electrophysiol. - 2010. - Vol. 3. - P. 32-38.

2. HRS/EHRA/ECAS/APHRS/SOLAECE expert consensus statement on catheter and surgical ablation of atrial fibrillation / Calkins H., Hindricks G., Cappato R. et al. // Heart Rhythm. - 2017. - Vol. 14. - P. 275-444.

3. Electrophysiological endpoint for catheter ablation of atrial fibrillation initiated from multiple pulmonary venous foci / Haissaguerre M. et al. // Circulation. - 2000. - Vol. 101 (12). - P. 1409-1417.

4. Circumferential radiofrequency ablation of pulmonary vein ostia: A new anatomic approach for curing atrial fibrillation / Pappone C. et al. // Circulation. - 2000. Vol. 102 (21). - P. 2619-2628.

5. Small or large isolation areas around the pulmonary veins for the treatment of atrial fibrillation? Results from a prospective randomized study / Arentz T. et al. // Circulation. - 2007. - Vol. 115 (24). - P. 3057-3063.

6. Buch E., Shivkumar K. Catheter Ablation of Atrial Fibrillation Advent of Second-Generation Technologies // Journal of the American college of cardiology. - 2015. Vol. 66. - № 12.- P. 1361-1363.

7. Ghosh J. M., Mcguire M. A. The Full Circle: Back into the Pulmonary Veins: A New Possibility in AF Ablation? // J Cardiovasc Electrophysiol. - September 2015. - Vol. 26. P. 1007-1008.

8. Pulmonary vein Re-isolation as a routine strategy / Dass M. et al. - UK, Cardiostim, 2016.

\title{
Pulmonary veins isolation with non-irrigated ablation catheters
}

\author{
Doronin A. ${ }^{1}$, Suslina Y. ${ }^{2}$, Riznyk A. ${ }^{2}$, Khanenova V. ${ }^{2}$, Marushko Y. ${ }^{2}$, Meshkova M. ${ }^{2}$ \\ ${ }^{1}$ Ukrainian National Medical Postgraduate Academy (Kyiv) \\ 2 Ukrainian Children's Cardiac Center (Kyiv)
}

The article analyzes our own experience of the pulmonary veins isolation during radiofrequency catheter ablation of atrial fibrillation (AF) with $4 \mathrm{~mm}$ tip non-irrigated catheters. The results of 145 primary AF catheter ablations in consecutive patients with paroxysmal AF have been analyzed. During the procedure after each 15-20 applications the ablation catheter was removed and wiped with a damp cloth.

The average time of X-ray exposure was $25.2 \pm 6.3 \mathrm{~min}$. The recurrence of AF in 1 year after ablation occurred in 43 (29.7\%) patients, another $1(0.7 \%)$ had a typical atrial flutter, 1 - atrial tachycardia, 1 - left atrial flutter. Sinus rhythm has been preserved without the use of antiarrhythmic drugs during the 1 year after procedure in $99(68.3 \%)$ patients. 
There were 4 (2.8\%) complications: 2 (1.4\%) cases of pericardial tamponade treated with pericardiocentesis and $2(1.4 \%)$ cases of pericardial effusion, which were treated conservatively. Thus, this technique is quite effective and safe.

Key words: atrial fibrillation, pulmonary veins isolation, efficiency.

\title{
Ізоляція гирл легеневих вен електродами без функції охолодження
}

\author{
Доронін О. В. ${ }^{1}$, Сусліна Ю. І. ${ }^{2}$, Різник О. С. ${ }^{2}$, Ханенова В. О. ${ }^{2}$, Марушко Е. Ю. ${ }^{2}$, Мешкова М. С. ${ }^{2}$ \\ ${ }^{1}$ Національна медична академія післядипломної освіти імені П. Л. Шупика (Київ) \\ ДУ «Науково-практичний медичний центр дитячої кардіології і кардіохірургії МОЗ України» (Київ)
}

У статті аналізується власний досвід ізоляції гирл легеневих вен при радіочастотній катетерній деструкції фібриляції передсердь (ФП) електродами 4 мм без функції охолодження. Проаналізовано результати 145 первинних послідовних катетерних деструкцій ФП у пацієнтів із пароксизмальною формою ФП. Після 15-20 аплікацій деструкційний електрод виймався і протирався.

Середній час рентген-експозиції склав $25,2 \pm 6,3$ хв. Рецидив ФП протягом одного року виник у $43(29,7 \%)$ пацієнтів, ше в одного $(0,7 \%)$ виникло типове тріпотіння передсердь, в одного - передсердна тахікардія,в одного - лівостороннє тріпотіння передсердь. Синусовий ритм зберігся без використання антиаритмічних препаратів упродовж року у $99(68,3 \%)$ пацієнтів.

Було 4 (2,8\%) ускладнення: $2(1,4 \%)$ випадки тампонади перикарда, які лікувалися шляхом перикардіоцентезу, і $2(1,4 \%)$ випадки випоту в перикарді, які лікувалися консервативно.

Таким чином, дана методика є достатньо ефективною та безпечною.

Ключові слова: фібриляція передсердь, ізоляція легеневих вен, успішність. 